\title{
Socio-ecological features other than sex affect habitat selection in the socially obligate monogamous Eurasian beaver
}

\author{
Sam M. J. G. Steyaert ${ }^{1,2} \cdot$ Andreas Zedrosser $^{2,3} \cdot$ Frank Rosell $^{2}$
}

Received: 14 August 2014 / Accepted: 30 June 2015 / Published online: 11 August 2015

(C) The Author(s) 2015. This article is published with open access at Springerlink.com

\begin{abstract}
Habitat selection is a context-dependent mechanism, in which both the internal state as well as external factors affect the behavior and decisions of an individual. This is well known for polygamous mammals, which are typically sexually dimorphic, and often express great variability in behavior and habitat selection between individuals as well between the sexes. Among monogamous mammals, however, variability in habitat selection should be explained by group characteristics and the presence of offspring rather than by sex. We evaluated this hypothesis in a socially monogamous rodent, the Eurasian beaver (Castor fiber), in a saturated Norwegian population. For the first time in this species we applied GPS tracking devices ( $N=22$ adult beavers, in 15 territories, 2009-2013), and used resource selection functions (i) to document
\end{abstract}

Communicated by Janne Sundell.

Electronic supplementary material The online version of this article (doi:10.1007/s00442-015-3388-1) contains supplementary material, which is available to authorized users.

Frank Rosell

frank.rosell@hit.no

Sam M. J. G. Steyaert

sam.steyaert@nmbu.no

Andreas Zedrosser

andreas.zedrosser@hit.no

1 Department of Ecology and Natural Resource Management, Norwegian University of Life Sciences, 1430 Ås, Norway

2 Faculty of Arts and Sciences, Department of Environmental and Health Studies, Telemark University College, 3800 B $\emptyset$, Norway

3 Institute of Wildlife Biology and Game Management, University of Natural Resources and Life Sciences, 1180 Vienna, Austria population-wide habitat selection and the importance of 'territory' therein, and (ii) to evaluate which socio-ecological factors explained potential individual differences in habitat selection. We found that variation in habitat selection was stronger between territories than between years or individuals nested by territory. We identified that family size and the presence of kits, but not sex, explained individual variation in habitat selection. Adults with kits and/ or larger families tended to exhibit low risk-taking behavior (avoiding human-related variables such as roads, buildings, and agricultural land), and stayed close to their main lodge (parental care). Our results show that habitat selection is a context-dependent mechanism even in a species which expresses very little behavioral and morphological dimorphism.

Keywords Habitat selection - Behavioral contexts · Monogamy $\cdot$ Eurasian beaver $\cdot$ Castor fiber

\section{Introduction}

Optimal habitat selection in animals should provide for their immediate and long-term needs, without jeopardizing their survival (Manly et al. 2002). This implies that habitat selection should be context-dependent (Boyce et al. 2002; Luttbeg and Sih 2010), based on an individual's internal state (e.g., reproductive status, sex, age, personality, etc.) and its external environment (e.g., climate, season, year, habitat quality, etc.) (Nathan et al. 2008). For example, vulnerability to predation can differ among individuals and can constrain habitat selection of more vulnerable individuals (Lima and Bednekoff 1998), reproductive strategies may diversify habitat selection and other behavior between the sexes or reproductive classes (Shuster and Wade 2003; 
Steyaert et al. 2013a, b, 2014), and group size and temporal variation in food availability may affect patterns in habitat selection (Johnson 1980; Fortin et al. 2009). Among mammals, such context-dependent habitat selection is more pronounced in polygamous than in monogamous species because of intersexual differences in behavior, morphology, and physiology. In polygamous species, males are typically larger than females, and have larger territories or home ranges or live spatiotemporally segregated from females, and paternal care is rare (Clutton-Brock 1989; Andersson 1994; Shuster and Wade 2003). In monogamous species, males and females are typically more similar in terms of body size and behavior, and paternal care is often essential to successfully raise offspring, especially in obligate monogamous species (Kleiman 1977; Gubernick and Teferi 2000; Reichard 2003). Consequently, one could expect that habitat selection is similar between the sexes in monogamous mammals.

Social monogamy implies a socio-spatial relationship in which a male and female stay together during at least one breeding season (Reichard 2003). Social monogamy is rare among mammals ( $\sim 3-9 \%$ of the species), and occurs mostly among canids, rodents, and primates (Kleiman 1977; Lukas and Clutton-Brock 2013). Socially monogamous species typically live in families and are territorial, implying that a dominant pair and their offspring share, maintain, and defend a single territory (Mathews 2002). This implies that habitat availability for family members is largely similar, if not identical. Therefore, patterns in habitat selection likely differ more strongly between individuals of different families than between family members. In addition to different habitat availability among territories, group size, habitat quality and resource availability, and the presence of offspring can also vary among territories, and thus should also influence patterns in habitat selection.

The socially obligate monogamous Eurasian beaver (Castor fiber) forms long-lasting breeding pairs, is territorial (Campbell et al. 2005), and both sexes contribute to territory maintenance (Rosell and Thomsen 2006) and parental care (Wilsson 1971). Beavers display little external sexual dimorphism, and adults of both sexes exhibit similar behaviour, although some division of labour has been observed (Wilsson 1971; Sharpe and Rosell 2003; Herr and Rosell 2004a; Rosell and Schulte 2004; Rosell and Thomsen 2006). Beavers are seasonal breeders, with a mating season from late January to early March, peaking around mid-February (Wilsson 1971). Kits are born around midMay (Parker and Rosell 2001), and spend their first 6 to 8 weeks in the lodge (Wilsson 1971). Lactation lasts approximately 3 months (Zurowski et al. 1974). Male parental care includes socializing, allogrooming, transporting kits, providing food, huddling, and active territory defense (Sharpe and Rosell 2003). Family size typically ranges from two to six individuals (Rosell et al. 2006). Both sexes usually disperse at the age of 2 years (Hartman 1997), when beavers reach sexual maturity (Wilsson 1971). Beavers are herbivorous generalists, and feed on bark, leaves, and shoots of woody plants (preferably deciduous species), as well as on herbs, ferns, and aquatic vegetation (Wilsson 1971; Haarberg and Rosell 2006). Beavers exhibit a nocturnal lifestyle, typically remaining in their lodges during the day, although they may also frequently return to their lodges during nighttime (Rosell and Hovde 2001; Sharpe and Rosell 2003).

Here, we investigated habitat selection in the Eurasian beaver in relation to socio-ecological contexts. We hypothesized that (1) habitat selection at the population level (i.e., the statistical population of adult beavers in our study area) would be more pronounced between territories than between individuals, and that (2) on the individual level, family size and the presence of kits would have a greater influence on habitat selection than sex or season. We tested our hypotheses in a Norwegian beaver population based on global positioning system (GPS) tracking and resource selection functions.

\section{Materials and methods}

\section{Study area}

The study was carried out on the Straumen, Gvarv, and Sauar river systems in Telemark County, southeast Norway. The rivers are between 30 and $150 \mathrm{~m}$ wide, and represent comparable habitat systems. The rivers have a regulated slow water flow, and meander through a rolling landscape of pastures, arable land, and boreal forest. All three rivers empty into Lake Norsjø, and Lake Nome and Lake Bråfjorden are contained within the Straumen and Sauar rivers, respectively. Beavers do not build dams in the study area, as the rivers are large enough to make dam-building unnecessary (Herr and Rosell 2004b). The riverbanks consist mostly of bare soil and herbaceous vegetation. The forest is dominated by Norway spruce (Picea abies), Scots pine (Pinus sylvestris), and birch species (Betula spp.); however, deciduous species such as grey alder (Alnus incana), rowan (Sorbus aucuparia), and willow (Salix spp.) dominate forested riverbanks (Haarberg and Rosell 2006). The climate is cold and wet, with a mean annual temperature of $4.6{ }^{\circ} \mathrm{C}$ and annual precipitation of $790 \mathrm{~mm}$. Elevations range from 15 to $70 \mathrm{~m}$ above sea level. Beavers resettled the study area in the 1920s, and the population is currently at carrying capacity (Rosell and Hovde 2001; Pinto et al. 2009). Today, hunting and trapping pressure is very low or nonexistent (Olstad 1937; Campbell et al. 2005). The Eurasian lynx (Lynx lynx) is the only natural predator, although it 
occurs at low densities (1996-2002: 0.2-0.4 lynx/100 km²) (Herfindal et al. 2005) and preys predominantly on species other than beavers (Odden et al. 2006).

\section{Trapping and sampling}

We captured and marked adult beavers between 2009 and 2013, following the capture and handling protocol by Rosell and Hovde (2001). Captures were concentrated in spring (March-May) and autumn (August-October) of each study year. The study population is subject to a longterm monitoring program in which territory-specific social data (family size, annual reproductive success) is routinely collected (Campbell et al. 2012, 2013). We assumed that an animal was resident in a territory if we observed it several times within the same territory during its monitoring period. We are confident that we assigned the correct territory to each study individual, as we included only dominant individuals in this study, and virtually all GPS relocations were within their previously assigned territory. We classified animals into age classes $(0$ years $=$ kit, 1 year $=$ yearling, 2 years $=$ sub-adults and $\geq 3$ years $=$ adult $)$ based on their body weight (Rosell et al. 2010; Campbell et al. 2013). We assigned the adult residents of each sex as the dominant pair. If additional adult candidates were present within a territory, we verified dominance based on eventual dispersal of alternative candidates, body weight and size, and lactation (i.e., female nipple length $>0.5 \mathrm{~cm}$ ). We assumed that dominant individuals maintained their status until they disappeared or died, absent evidence to the contrary (Campbell et al. 2012).

We aimed to capture the dominant pair of a territory at least once during the study, and deployed a rechargeable archival $\mu$ GPS receiver (24 g, 20-day battery life) (model G1G 134A; Sirtrack, Havelock North, New Zealand, http:// www.sirtrack.com). We also deployed a VHF transmitter (Reptile glue-on, series R1910; Advanced Telemetry Systems, Isanti, MN, USA), with a weight of $10 \mathrm{~g}$, to track the animals for re-capture or to find lost devices. We glued the GPS and VHF units on the fur of the lower back with a two-component epoxy resin. We chose this part of the body for deployment, because it lies higher in the water surface when beavers swim and allows for better aerial sighting. We used a coarsely meshed polyester net to cover the units in order to prevent removal by the animal. We retrieved the GPS devices by recapturing the animals and cutting the device from the fur using a scalpel. We scheduled the GPS devices to fix one GPS location every $15 \mathrm{~min}$ between 1900 and 700 hours, given the nocturnal activity period of beavers (Sharpe and Rosell 2003). We discarded GPS relocations that were obtained on the days of capture and re-capture to avoid observer and capture-related bias in the data. Our capture and handling procedures, however, appear to have only minor behavioral effects, since beavers typically resume their normal activities within $15 \mathrm{~min}$ after their release (Sharpe and Rosell 2003). Long-term monitoring of our study animals does not affect reproductive success, lactation, or mothering ability (Ranheim 2004), and capturing and handling beavers has no significant effect on their body condition ( 252 beavers, 729 recaptures) (Farrell 2014). We screened the GPS data to improve spatial accuracy, according to Lewis et al. (2007). Successful GPS fixes were obtained only when a beaver was outside the lodge. All animal handling procedures were approved by the appropriate Norwegian authorities, the Norwegian Directorate for Nature Management and the Norwegian Animal Research Authority (Forsøksdyrutvalget, NARA/FDU).

\section{Data analyses}

We used resource selection functions (RSFs) to (i) identify habitat selection on the population level and determine the importance of 'territory', 'individual', and 'year' therein, and to (ii) evaluate how sex, the presence of kits, and family size influence habitat selection on the individual level. RSFs contrast habitat 'use' with habitat 'availability', which is typically represented by a set of animal relocations (GPS data) and a set of random points, respectively. Subsequently, the use and availability data can be linked to spatial data layers (land cover type, slope steepness, etc.) in a geographical information system, and statistical methods (e.g., logistic regression) can be used to determine which and how landscape characteristics influence resource selection (Aarts et al. 2012). For details on the RSF methodology, see Lele et al. (2013). We sampled habitat use and habitat availability in a 1:1 ratio, within the $100 \%$ minimum convex polygon (MCP) estimated territory of each individual beaver during the period of monitoring.

For each location, we derived the following landscape variables from a continuously updated digital topographic map (Felles KartDatabase, FKB data Geovekst, http:// www.kartverket.no/) of the study area: land cover ['forest', 'build-up' (land covered with buildings), 'water', 'agriculture', 'mire', 'other'], slope steepness, river or lake associated (if the nearest water body to a certain location was a lake or a river, we defined lakes and river based on their administrative classification), distance to the nearest water body (for locations on land), distance to the nearest land (for locations in the water), and distance to roads, buildings, and to the main lodge. We considered these landscape variables as fixed effects in mixed effect regression models.

For habitat selection on the population level, we used 'use' vs. 'availability' as the binomial response variable, and included 'beaver ID' nested in 'territory ID' as random factors on the intercept. Because climate and climatic variation can influence recruitment in beavers (Campbell et al. 
2012), we included 'year' as a random factor. We formulated six candidate models a priori (Electronic Supplementary Material Table A1), and used second-order biascorrected Akaike information criteria $\left(\mathrm{AIC}_{\mathrm{c}}\right.$ ) differences $\left(\triangle \mathrm{AIC}_{\mathrm{c}}\right)$ and weights $\left(\mathrm{AIC}_{\mathrm{wt}}\right)$ to select the most parsimonious model (Anderson 2008). The variables 'land cover' and 'river/lake associated' were considered as categorical variables, whereas the 'distance to' variables were considered as continuous variables. We considered models with $\Delta \mathrm{AIC}_{\mathrm{c}}$ values $>2$ as inconclusive. We evaluated the relative importance of each model term of the most parsimonious model based on $\triangle \mathrm{AIC}_{\mathrm{c}}$ scores after systematically including/excluding model components. We validated the most parsimonious model using a tenfold cross-validation procedure following Boyce et al. (2002). We chose 0.6 as the threshold level for evaluating collinearity among explanatory variables. We multiplied the parameter estimates of the 'distance to the nearest...' variables by -1 to facilitate interpretation, with positive values indicating selection and negative values indicating avoidance.

For habitat selection on the individual level, we aimed to explain variance in habitat selection among individuals in relation to socio-ecological factors. Therefore, we created individual-based RSFs with respect to a fixed set of landscape variables; all 'distance to the nearest...' variables and the land cover classes that occurred in all $100 \% \mathrm{MCP}$ territory. For each beaver, we sampled use/availability in a 1:1 ratio, and within its $100 \%$ MCP territory. The parameter estimates $(\beta)$ and standard errors $(\sigma)$ for each model variable indicate whether a certain variable is selected for, selected against, or is of relative unimportance in an individual's habitat selection, and can be considered as selection coefficients for individual behavioral responses (Compton et al. 2002). We summarized these behavioral responses of the individual RSFs, and linked them with data of each individual beaver, year of monitoring, season of monitoring (spring/autumn), sex, the presence of kits (yes/no), territory size (100\% MCP estimated territory size based on valid GPS relocations), and family size (total number of beavers in the colony). We evaluated the model fit of the individual RSFs using the dispersion parameter (residual deviance/degrees of freedom, should be close to 1). For each individual, we obtained behavioral responses for 'slope', distance to 'roads', 'buildings', 'water', 'land', and 'lodges', and land cover types 'agriculture', 'forest', 'mire', and 'water'. We did not obtain behavioral responses for 'river or lake associated' because of singularities, or for the land cover types 'other' and 'build-up' because of their absence in some of the territories. We used these behavioral responses, as well as territory size, as response variables in linear regression models, and considered 'season of monitoring' and the social factors 'sex', 'family size', 'presence of kits', and the interaction 'presence of kits $\times$ sex' as explanatory variables. We have not included the variable 'year' at this stage of the analysis, because of singularities and a potentially confounding relationship with 'beaver ID'. For the behavioral responses to the land cover classes, we also included the availability of a given land cover type in each beaver's territory to account for a potential functional response (Mysterud and Ims 1998). For these post hoc analyses, we ran all possible model combinations, and selected the most parsimonious model based on the $\triangle \mathrm{AIC}_{\mathrm{c}}$ and $\mathrm{AIC}_{\mathrm{cw}}$ scores (Burnham and Anderson 2002). Based on the principle of parsimony, and to avoid including 'pretending variables' in the model results, we selected the simplest model within the $\Delta \mathrm{AIC}_{\mathrm{c}}$ range of 0-2 (Anderson 2008). We used a linear mixed-effect regression model with the number of valid daily GPS relocations per individual as the response variable, 'sex' as a fixed effect, and 'beaver ID' as a random effect on the intercept to test whether the number of valid GPS relocations differed between the sexes, and we used a linear model to evaluate the relationship between the total number of days that an individual was monitored and 'sex'. We validated the most parsimonious models by plotting the model residuals versus the fitted values (Zuur et al. 2009). We used R 2.15.0 software for all statistical analyses (R Development Core Team 2013).

\section{Results}

We obtained GPS relocation data for 22 dominant beavers (12 males, 10 females) among 15 territories (Table 1). With the exception of one male (Erlend), all beavers were monitored during a single year and a single season. We managed to simultaneously monitor the dominant pair of a territory on five occasions (Territory B1, spring 2010; LP, autumn 2010; P0, autumn 2010; P1, autumn 2013; P3b, autumn 2010) (Table 1). Beavers were monitored on average for $13.5 \pm 4.5(8-25)$ days before the GPS units were retrieved. The average number of successful GPS fixes per individual was $361 \pm 158$ (range 158-689) (Table 1). There was no difference between the sexes in either the number of daily GPS relocations per individual or the number of monitoring days per individual (daily relocations: $\beta=-1.3$, $\sigma=2.69, \mathrm{LL}=-6.59, \mathrm{UL}=3.99, \Delta \mathrm{AIC}_{\mathrm{c}}=-1.93$; monitoring days: $\beta=-2.2, \sigma=2.96, \mathrm{LL}=-8.00, \mathrm{UL}=3.61$, $\left.\Delta \mathrm{AIC}_{\mathrm{c}}=2.06\right)$. No collinearity was apparent in the data.

\section{Habitat selection on the population level}

The full model was the most parsimonious $\left(\mathrm{AIC}_{\mathrm{cw}}=1\right)$ of the six a priori defined candidate models. All other candidates were inconclusive (all $\triangle \mathrm{AIC}_{\mathrm{c}}$ scores $>85$ ). The strongest predictors of beaver habitat selection were the distance to water while a beaver was on land and the 
Table 1 Meta-data of the dominant GPS-marked beavers used in this study in Telemark County, Norway, from 2009 to 2013

\begin{tabular}{|c|c|c|c|c|c|c|c|c|}
\hline Beaver & Territory & Sex & $N_{\text {pos }}$ & $N_{\text {day }}$ & Year & Season & \# kits & Family size \\
\hline Leslie & B1 & $\mathrm{F}$ & 679 & 19 & 2010 & $\mathrm{~s}$ & 0 & 2 \\
\hline Andreas & B1 & M & 275 & 10 & 2010 & $\mathrm{~s}$ & 0 & 2 \\
\hline Moritz & B2 & M & 168 & 8 & 2010 & $\mathrm{a}$ & 0 & 3 \\
\hline Hazel & $\mathrm{G}$ & $\mathrm{F}$ & 682 & 25 & 2010 & $\mathrm{~s}$ & 0 & 8 \\
\hline Paddy & G & M & 375 & 12 & 2012 & $\mathrm{~s}$ & 3 & 6 \\
\hline Lasse & L2 & M & 325 & 11 & 2011 & $\mathrm{~s}$ & 1 & 5 \\
\hline Loran & $\mathrm{L} 4 \mathrm{a}$ & M & 412 & 13 & 2009 & $\mathrm{a}$ & 0 & 3 \\
\hline Maud & L6a & $\mathrm{F}$ & 392 & 12 & 2009 & $\mathrm{a}$ & 0 & 2 \\
\hline Bram & L6a & M & 158 & 8 & 2011 & $\mathrm{~s}$ & 0 & 3 \\
\hline Ida & LP & $\mathrm{F}$ & 383 & 14 & 2010 & $\mathrm{a}$ & 2 & 5 \\
\hline Kjartan & LP & M & 216 & 9 & 2010 & $\mathrm{a}$ & 2 & 5 \\
\hline Jodie & N1 & $\mathrm{F}$ & 388 & 13 & 2012 & $\mathrm{~s}$ & 1 & 5 \\
\hline Hanna Synnøve & $\mathrm{P} 0$ & $\mathrm{~F}$ & 257 & 12 & 2010 & $\mathrm{a}$ & 1 & 4 \\
\hline Jan Marc & P0 & M & 384 & 14 & 2010 & $\mathrm{a}$ & 1 & 4 \\
\hline Live & P1 & $\mathrm{F}$ & 249 & 21 & 2013 & $\mathrm{a}$ & 1 & 5 \\
\hline Manuel & P1 & M & 297 & 11 & 2013 & $\mathrm{a}$ & 1 & 5 \\
\hline Apple & $\mathrm{P} 2 \mathrm{a}$ & $\mathrm{F}$ & 689 & 18 & 2013 & $\mathrm{a}$ & 0 & 5 \\
\hline Leigh & P2a & $\mathrm{F}$ & 180 & 9 & 2010 & $\mathrm{a}$ & 1 & 4 \\
\hline Moses & $\mathrm{P} 2 \mathrm{~b}$ & M & 279 & 14 & 2010 & $\mathrm{a}$ & 2 & 5 \\
\hline Christina & P3a & $\mathrm{F}$ & 459 & 19 & 2010 & $\mathrm{a}$ & 0 & 3 \\
\hline Erlend & $\mathrm{P} 3 \mathrm{~b}$ & M & 446 & 15 & 2010 & $\mathrm{a}$ & 0 & 2 \\
\hline Erlend & $\mathrm{P} 3 \mathrm{~b}$ & M & 437 & 17 & 2013 & $\mathrm{~s}$ & 0 & 2 \\
\hline Horst & P4 & M & 171 & 8 & 2010 & $\mathrm{a}$ & 1 & 3 \\
\hline
\end{tabular}

Territory territory identifier, sex ( $m$ male, $f$ female), $N_{\text {pos }}$ number of valid GPS relocations per individual, $N_{d a y}$ number of monitoring days per individual. Year year of monitoring, Season ( $s$ spring, $a$ autumn), No. kits the number of kits in the family, Family size the total number of family members in a given territory during the period of monitoring distance to land while a beaver was in the water (Table 2). Beavers generally selected their habitat relatively close to the river bank (median, mean, and 95th percentile for GPS locations on land were $15,24.8$, and $77 \mathrm{~m}$, respectively, and 13, 17, and $49 \mathrm{~m}$ for GPS locations in the water, respectively) (Electronic Supplementary Material Fig. A1). Land cover type was an important determinant of beaver habitat selection. With build-up areas as a reference, water bodies, mires, and forests were selected for, whereas agricultural areas and other land cover types were neither selected for nor against (Table 2). Relative to random locations, beavers selected areas close to roads and far from their lodges (Table 2). They generally preferred areas in or close to rivers over areas in or close to lakes, and selected for gentle slopes (Table 2). Buildings had no apparent effect on habitat selection, and excluding 'distance to the nearest building' from the full model would have resulted in a slightly better model fit (Table 2). Habitat selection varied considerably more ( $\sim 6$ times) between territories (random effect variance $=0.118$ ) than between individual beavers (random effect variance $=0.0196$ ) or years (random effect variance $=0.0198$ ). The full model had good predictive accuracy (tenfold cross-validation coefficient $=0.89$ )

\section{Habitat selection on the individual level}

The individual-based RSFs had dispersion parameters between 0.72 and 1.19 , indicating good model fit. Territory size and selection for 'slope steepness', the land cover type 'mire', and selection in relation to 'distance to water' was not related to social characteristics in beavers (Table 3). 'Family size' was included in the top-ranked models for 3 of 11 behavioral types. Adults of larger families ( 8 individuals) selected their habitat closer to the lodge than adults of smaller families ( 2 individuals, Table 1$)$ (Table 3, Electronic Supplementary Material Fig. A2-4). Adults of larger families selected their habitat further from the bank when in the water, and avoided areas close to buildings more strongly than adults from smaller families (Table 3, Electronic Supplementary Material Fig. A2-4). Families with kits avoided agricultural areas and roads to a greater degree than families without kits (Table 3). In general, beavers showed a negative functional response for 
Table 2 Fixed effects of the most parsimonious model for estimating population-wide habitat selection of Eurasian beavers in Telemark, southern Norway (2009-2013)

\begin{tabular}{|c|c|c|c|c|c|}
\hline Model term & $\beta$ & $\sigma$ & LL & UL & $\Delta \mathrm{AIC}_{\mathrm{c}}$ \\
\hline \multicolumn{6}{|l|}{ Distance to } \\
\hline Intercept & 0.6574 & 0.2269 & 0.213 & 1.102 & \\
\hline Road & 0.0011 & 0.0003 & 0.001 & 0.002 & 72.1 \\
\hline Lodge & -0.0005 & 0.0001 & -0.0007 & -0.0003 & 17 \\
\hline Land & 0.0441 & 0.0014 & 0.041 & 0.047 & 1723.5 \\
\hline Building & 0.0001 & 0.0003 & -0.0005 & 0.0007 & -1.68 \\
\hline Water & 0.0283 & 0.0008 & 0.027 & 0.03 & 2056.4 \\
\hline Slope steepness & -0.0137 & 0.003 & -0.02 & -0.008 & 66.55 \\
\hline \multicolumn{6}{|l|}{ Habitat type } \\
\hline River vs. lake & 0.3525 & 0.0607 & 0.234 & 0.471 & 59.27 \\
\hline $\begin{array}{l}\text { Water vs. } \\
\text { build-up }\end{array}$ & 0.8927 & 0.1861 & 0.528 & 1.257 & 315.5 \\
\hline $\begin{array}{l}\text { Mire vs. } \\
\text { build-up }\end{array}$ & 0.6002 & 0.218 & 0.173 & 1.027 & \\
\hline $\begin{array}{l}\text { Forest vs. } \\
\text { build-up }\end{array}$ & 0.6044 & 0.1815 & 0.249 & 0.96 & \\
\hline $\begin{array}{l}\text { Agriculture vs. } \\
\text { build-up }\end{array}$ & -0.3545 & 0.1882 & -0.723 & 0.014 & \\
\hline $\begin{array}{l}\text { Other vs. } \\
\text { build-up }\end{array}$ & -0.0188 & 0.199 & -0.409 & 0.371 & \\
\hline
\end{tabular}

Large values indicate high relative importance of a certain model term. LL and UL represent the lower and upper $95 \%$ confidence levels around the parameter estimate $(\beta \pm 1.96 \times \sigma)$. Positive $\beta$ values indicate selection for, whereas negative values indicate selection against

$\beta$ parameter estimate, $\sigma$ standard error, $\triangle A I C_{c}$ Akaike information criterion difference calculated separately for each model term with respect to the full model the land cover types 'water' and 'forest': the scarcer these land cover types, the more strongly individuals selected for them (Table 3). Sex and season were never included in the most parsimonious models (Table 3 ). No heteroskedasticity was present in the models.

\section{Discussion}

Our results support hypothesis (1), because habitat selection varied considerably more ( $\sim 6$ times) among territories than among individual beavers or years. We also found support for hypothesis (2, as family size and the presence of kits best explained variation in habitat selection and behavior, and that habitat selection did not differ between the sexes. Concurrent with the theory (Mysterud and Ims 1998), beavers also exhibited a functional response for forest and water: the scarcer these resources, the more strongly they were selected for.

\section{Habitat selection on the population level}

The general patterns of habitat selection was consistent with expectations for an aquatic rodent: a very strong link to the river bank or lakeshore, forest and mires or swamps, and a tendency to avoid steep surfaces (Collen and Gibson 2000). We suggest two possible explanations why beavers selected for areas far from their lodges. Central-place foraging implies that individuals must bring their food items to a central place for processing, storage, or consumption (Orians and Pearson 1979). For beavers, such a central place

Table 3 Most parsimonious model outcomes that relate selection behaviors and territory size (response variable) to socio-ecological factors ('season of monitoring', 'sex', 'family size', 'presence of kits', and the interaction 'sex $\times$ presence of kits')

\begin{tabular}{|c|c|c|c|c|c|c|c|}
\hline Response variable & Model term (s) & $\beta$ & $\sigma$ & LL & UL & $\Delta \mathrm{AIC}_{\mathrm{c}}$ & $R^{2}$ \\
\hline Slope steepness & - & - & - & - & - & - & - \\
\hline Territory size & - & - & - & - & - & - & - \\
\hline Land cover type: 'mire' & - & - & - & - & - & - & - \\
\hline Land cover type: 'agriculture' & Presence of kits & -0.44 & 0.09 & -0.616 & -0.264 & 12.1 & 0.17 \\
\hline Land cover type: 'water' & Availability of water & -0.595 & 0.201 & -0.989 & -0.201 & 5.4 & 0.30 \\
\hline Land cover type: 'forest' & Availability of forest & -1.051 & 0.247 & -1.535 & -0.567 & 11.7 & 0.10 \\
\hline Distance to the nearest road & Presence of kits & -0.004 & 0.002 & -0.008 & 0.000 & 4.0 & 0.25 \\
\hline Distance to the nearest lodge & Family size & 0.001 & 0.0004 & 0.000 & 0.002 & 5.2 & 0.29 \\
\hline Distance to the nearest land & Family size & -0.007 & 0.002 & -0.011 & -0.003 & 10.7 & 0.44 \\
\hline Distance to the nearest building & Family size & -0.002 & 0.001 & -0.004 & 0.000 & 3.5 & 0.23 \\
\hline Distance to the nearest water & Family size & 0.005 & 0.002 & 0.001 & 0.009 & 0.8 & 0.13 \\
\hline
\end{tabular}

LL and UL represent the $95 \%$ confidence levels around the parameter estimate $(\beta \pm 1.96 \times \sigma)$. Note that $\Delta \mathrm{AIC}_{\mathrm{c}}$ values $<2$ indicate uninformative model terms. $B$ parameter estimate, $\sigma$ standard error, $\triangle A I C_{c}$ Akaike information criterion difference values relative to the second most parsimonious model 
implies the river bank or lakeshore, as well as their lodge. Beavers generally move out of the water to select their food items on land, and transport them back to the water to consume directly or to the lodge to feed their offspring or to store for later use (Schoener 1979; Jenkins 1980; McGinley and Whitham 1985; Basey et al. 1988; Fryxell and Doucet 1991; Haarberg and Rosell 2006). However, in territories that have been stable and maintained over several generations, food depletion near the main lodge may force beavers to select their resources far from the lodge (Fryxell and Doucet 1991; Collen and Gibson 2000). Secondly, territory maintenance (scent marking), patrol, and defense should be most concentrated in areas where the probability of intrusion is highest, at the up- and downstream border zones (Rosell et al. 1998; Herr and Rosell 2004a). These border zones are typically far from the main lodge.

Surprisingly, we found that beavers generally tended to select areas close to roads. We suggest that beavers, like many omnivores and other herbivores, are attracted to nutritious herbaceous roadside vegetation (Forman and Alexander 1998). Distance to roads was not spatially correlated with distance to water or other landscape variables, suggesting that preference for roads was an independent factor. Investigation of the random model terms and individual-based RSFs, however, suggested that habitat selection was more complex, and varied among individuals according to their socio-ecological situation.

\section{Habitat selection on the individual level}

Family size and the presence of kits were important socioecological factors that affected habitat selection on the individual level. We suggest that adult beavers with large families and/or kits alter their habitat selection according to the parental care required to successfully raise their offspring. For example, adults with kits should return to the lodge more frequently to feed, or to huddle and provide body warmth to their kits, than beavers without kits (Sharpe and Rosell 2003; Sun 2003). Seasonal variation appeared to be relatively unimportant in habitat selection behavior among beavers.

Life history theory predicts that, in order to increase offspring survival, individuals with dependent offspring should be less willing to expose themselves to risk than individuals without dependent young (Stearns 1989; Lima and Dill 1990). Our results concur with this prediction, because we observed that adult beavers of larger families and/or with kits were more likely to avoid areas with a high risk of meeting humans (agricultural areas, and roads) than adults of smaller families or without kits. Predation, hunting, and exploitation can have long-lasting behavioral and evolutionary effects on wildlife populations (Creel et al. 2007; Proaktor et al. 2007; Zedrosser et al. 2011). Even if human hunting and natural predation are currently low in our study population, such lasting risk avoidance effects are not surprising. Past research has documented that beavers decreased their foraging activity and scent-marking behavior in the presence of experimentally applied predator [wolf (Canis lupus), brown bear (Ursus arctos), river otter (Lutra lutra), red fox (Vulpes vulpes), and lynx] odors (Rosell and Czech 2000; Rosell and Sanda 2006). Behavioral differences between individuals of different reproductive status or presence of offspring should be expected, considering that paternal care is an extremely important factor in shaping the general ecology of a species (Andersson 1994). Such behavioral differences have been documented in a range of species, including those with both monogamous and polygamous mating systems. For example, spatiotemporal behavior of wolves is concentrated around a central place (den or rendezvous sites) during the summer, when the pups are fully dependent on their pack mates, whereas they have a more nomadic lifestyle when no dependent young are present (Boitani 2003). Similarly, female brown bears with dependent offspring alter their habitat selection compared to lone females in order to reduce infanticide risk (Steyaert et al. 2013a, b).

\section{The absence of 'sex' in the models}

The factor 'sex' was never included in the most parsimonious models. Our results concur with previous research on both Eurasian and North American beavers (C. canadensis), which suggests that the two sexes of adult dominant beavers exhibit very similar behavior in terms of use of space within a given territory (Hodgdon and Lancia 1983; Busher and Jenkins 1985; Sharpe and Rosell 2003; Herr and Rosell 2004b; Busher 2007).

Behavioral variation between the sexes is common in polygamous, sexually dimorphic species (Ruckstuhl and Neuhaus 2005), and is generally explained by different parental investments by males and females. Females can optimize their reproductive success by safeguarding the survival and primary needs of their dependent offspring, whereas the behavior of the males is typically not constrained by the presence of young. This is referred to as the 'reproductive strategy hypothesis' in the sexual segregation literature (Bowyer 2004; Ruckstuhl and Neuhaus 2005; Ruckstuhl 2007; Main 2008), and evidence for this hypothesis has been documented in a range of ungulates and carnivores (Ruckstuhl and Neuhaus 2005; Main 2008; Steyaert et al. 2013a, b).

Theory predicts that the two sexes in monogamous species are less dimorphic in size and behavior than those in polygamous species (Kleiman 1977). However, sex differences can never completely disappear (Magurran and Garcia 2000). For example, lactation is an extremely costly process for females (Millar 1977), and influences use of space and behavior in many - if not all-mammals (Cost et al. 2014). In beavers, male investment in 
the family is mostly allocated to construction behavior, territory maintenance (scent marking and defense) (Rosell and Thomsen 2006), and alarm behaviors (Busher 2007). We could not detect such a difference between the sexes. Possible explanations for this might be that males and females are, indeed, very similar in terms of behavior and use of space, implying that males play an important role in parental care (Sun 2003), that behavioral differences such as nursing are predominantly expressed in the lodge (outside direct view/lost GPS connection), or that such differences are simply not detected with the use of GPS data.

\section{Conclusions}

We found that differences in habitat selection behavior in beavers were more pronounced between than within territories. These differences were related to family size and the presence of kits, but not to sex. In addition, beavers showed a functional response to certain habitat types, which indicates that part of the behavioral variation among the territories can be explained by variation in habitat availability. The behavior of adult beavers reflected strategies to optimize reproductive success; in the presence of kits and/ or larger families, adults tended to exhibit low risk-taking behavior (avoiding human-related variables such as roads, buildings, and agricultural land), and stayed relatively close to the main lodge (suggesting parental care by both sexes). Our results add to the growing body of evidence that habitat selection behavior is dependent on an organism's internal and external contexts, even in a species which expresses very little behavioral and morphological dimorphism.

Acknowledgments We thank Patricia Graf, Manuel Echeveria, Anders Mydland, Alex Enoksen, and Christian Andre Robstad for assistance with the fieldwork. This study was financed by Telemark University College.

Author contribution statement SMJGS, AZ, and FR developed the idea, FR conducted and coordinated the fieldwork, SMJGS conductedthe analyses, SMJGS, AZ, and FR wrote the manuscript.

Open Access This article is distributed under the terms of the Creative Commons Attribution 4.0 International License (http://creativecommons.org/licenses/by/4.0/), which permits unrestricted use, distribution, and reproduction in any medium, provided you give appropriate credit to the original author(s) and the source, provide a link to the Creative Commons license, and indicate if changes were made.

\section{References}

Aarts G, Fieberg J, Matthiopoulos J (2012) Comparative interpretation of count, presence-absence and point methods for species distribution models. Methods Ecol Evol 3(1):177-187

Anderson DR (2008) Model based inference in the life sciences, a primer on evidence. Springer, New York
Andersson M (1994) Sexual selection. Princeton University Press, New Jersey

Basey J, Jenkins S, Busher P (1988) Optimal central-place foraging by beavers: tree-size selection in relation to defensive chemicals of quaking aspen. Oecologia 76(2):278-282

Boitani L (2003) Wolf conservation and ecology. In: Mech DL, Boitani L (eds) Wolves: behavior, ecology and conservation. The Chicago University Press, Chicago, pp 317-340

Bowyer RT (2004) Sexual segregation in ruminants: definitions, hypothesis, and implications for conservation and management. J Mammal 85(6):1039-1052

Boyce MS, Vernier PR, Nielsen SE, Schmiegelow FKA (2002) Evaluating resource selection functions. Ecol Model 157:281-300

Burnham KP, Anderson DR (2002) Model selection and multimodel inference: a practical information-theoretic approach, 2nd edn. Springer, New York

Busher PE (2007) Social organization and monogamy in the beaver. In: Wolff JO, Sherman PW (eds) Rodent societies, Chap 24. University of Chicage Press, pp 280-290

Busher P, Jenkins S (1985) Behavioral patterns of a beaver family in California. Biol behav 10(1):41-54

Campbell RD, Rosell F, Nolet BA, Dijkstra VAA (2005) Territory and group sizes in Eurasian beavers (Castor fiber): echoes of settlement and reproduction? Behav Ecol Sociobiol 58(6):597-607

Campbell RD, Nouvellet P, Newman C, Macdonald DW, Rosell F (2012) The influence of mean climate trends and climate variance on beaver survival and recruitment dynamics. Glob Change Biol 18(9):2730-2742

Campbell RD, Newman C, Macdonald DW, Rosell F (2013) Proximate weather patterns and spring green-up phenology effect Eurasian beaver (Castor fiber) body mass and reproductive success: the implications of climate change and topography. Glob Change Biol 19(4):1311-1324

Clutton-Brock TH (1989) Review lecture: mammalian mating systems. Proc R Soc B 236(1285):339-372

Collen P, Gibson RJ (2000) The general ecology of beavers (Castor spp.), as related to their influence on stream ecosystems and riparian habitats, and the subsequent effects on fish-a review. Rev Fish Biol Fish 10(4):439-461

Compton BW, Rhymer JM, McCollough M (2002) Habitat selection by wood turtles (clemmys insculpta): an application of paired logistic regression. Ecology 83(3):833-843

Cost KT, Lobell TD, Williams-Yee ZN, Henderson S, Dohanich G (2014) The effects of pregnancy, lactation, and primiparity on object-in-place memory of female rats. Horm Behav 65(1):32-39

Creel S, Christianson D, Liley S, Winnie JA (2007) Predation risk affects reproductive physiology and demography of elk. Science 315(5814):960

Farrell SS (2014) The long-term effect of capture stress on the body condition in the Eurasian Beaver, Castor fiber. MSc thesis, The University of Edinburgh, Easter Bush

Forman R, Alexander L (1998) Roads and their major ecological effects. Annu Rev Ecol Syst 29(1):207-231

Fortin D, Fortin M-E, Beyer HL, Duchesne T, Courant S, Dancose K (2009) Group-size-mediated habitat selection and group fusion-fission dynamics of bison under predation risk. Ecology 90(9):2480-2490

Fryxell JM, Doucet CM (1991) Provisioning time and central-place foraging in beavers. Can J Zool 69(5):1308-1313

Gubernick DJ, Teferi T (2000) Adaptive significance of male parental care in a monogamous mammal. Proc Biol Sci 267(1439):147-150

Haarberg O, Rosell F (2006) Selective foraging on woody plant species by the Eurasian beaver (Castor fiber) in Telemark, Norway. J Zool 270(2):201-208

Hartman G (1997) Notes on age at dispersal of beaver (Castor fiber) in an expanding population. Can J Zool 75(6):959-962 
Herfindal I, Linnell JDC, Moa PF, Odden J, Austmo LB, Andersen $\mathrm{R}$ (2005) Does recreational hunting of lynx reduce depredation losses of domestic sheep? J Wildl Manag 69(3):1034-1042

Herr J, Rosell F (2004a) Use of space and movement patterns in monogamous adult Eurasian beavers (Castor fiber). J Zool 262(03):257-264

Herr J, Rosell F (2004b) Use of space and movement patterns in monogamous adult Eurasian beavers (Castor fiber). J Zool 262(3):257-264

Hodgdon H, Lancia R (1983) Behavior of the North American beaver, Castor Canadensis. Acta Zool Fenn 103:99-103

Jenkins SH (1980) A size-distance relation in food selection by beavers. Ecology 61(4):740-746

Johnson DH (1980) The comparison of usage and availability measurements for evaluating resource preference. Ecology 61(1):65-71

Kleiman DG (1977) Monogamy in mammals. Q Rev Biol 52(1):39-69

Lele SR, Merrill EH, Keim J, Boyce MS (2013) Selection, use, choice and occupancy: clarifying concepts in resource selection studies. J Anim Ecol 82(6):1183-1191

Lewis JS, Rachlow JL, Garton EO, Vierling LA (2007) Effects of habitat on GPS collar performance: using data screening to reduce location error. J Appl Ecol 44(3):663-671

Lima SL, Bednekoff PA (1998) Temporal variation in danger drives antipredator behavior: the predation risk allocation hypothesis. Am Nat 153(6):649-659

Lima SL, Dill LM (1990) Behavioral decisions made under the risk of predation: a review and prospectus. Can J Zool 68(4):619-640

Lukas D, Clutton-Brock TH (2013) The evolution of social monogamy in mammals. Science 341(6145):526-530

Luttbeg B, Sih A (2010) Risk, resources and state-dependent adaptive behavioural syndromes. Philos Trans R Soc B Biol Sci 365(1560):3977-3990

Magurran AE, Garcia CM (2000) Sex differences in behaviour as an indirect consequence of mating system. J Fish Biol 57(4):839-857

Main MB (2008) Reconciling competing ecological explanations for sexual segregation in ungulates. Ecology 89(3):693-704

Manly B, McDonald L, Thomas DL, McDonald TL, Erickson WP (2002) Resource selection by animals: statistical design and analysis for field studies. Kluwer Academic Publishers, Dordrecht

Mathews LM (2002) Territorial cooperation and social monogamy: factors affecting intersexual behaviours in pair-living snapping shrimp. Anim Behav 63(4):767-777

McGinley M, Whitham T (1985) Central place foraging by beavers (Castor canadensis): a test of foraging predictions and the impact of selective feeding on the growth form of cottonwoods (Populus fremontii). Oecologia 66(4):558-562

Millar JS (1977) Adaptive features of mammalian reproduction. Evolution 31(2):370-386

Mysterud A, Ims RA (1998) Functional responses in habitat use: availability influences relative use in trade-off situations. Ecology 79(4):1435-1441

Nathan R, Getz W, Revilla E, Holyoak M, Kadmon R, Saltz D, Smouse P (2008) A movement ecology paradigm for unifying organismal movement research. Proc Natl Acad Sci USA 105:19052-19059

Odden J, Linnell JC, Andersen R (2006) Diet of Eurasian lynx, Lynx lynx, in the boreal forest of southeastern Norway: the relative importance of livestock and hares at low roe deer density. Eur J Wildl Res 52(4):237-244

Olstad O (1937) Beverens (Castor fiber) utbredelse i Norge. Statens viltunders $\emptyset$ kelser. Nytt Mag Naturvidensk 77:217-273

Orians GH, Pearson NE (1979) On the theory of central place foraging. In: Horn DJ, Mitchell RD, Stairs GR (eds) Analysis of ecological systems. Ohio State University Press, Columbus, pp 155-177

Parker H, Rosell F (2001) Parturition dates for Eurasian beaver Castor fiber: when should spring hunting cease? Wildl Biol 7(3):237-241

Pinto B, Santos MJ, Rosell F (2009) Habitat selection of the Eurasian beaver (Castor fiber) near its carrying capacity: an example from Norway. Can J Zool 87(4):317-325

Proaktor G, Coulson T, Milner-Gulland EJ (2007) Evolutionary responses to harvesting in ungulates. J Anim Ecol 76(4):669-678

R Development Core Team (2013) R: a language and environment for statistical computing. R Foundation for Statistical Computing, Vienna. ISBN 3-900051-07-0. http://www.R-project.org/

Ranheim B, Rosell F, Haga HA, Arnemo JM (2004) Field anaesthetic and surgical techniques for implantation of intraperitoneal radio transmitters in Eurasian beavers Castor fiber. Wildl Biol 10(1): $11-15$

Reichard UH (2003) Monogamy: past and present. In: Reichard UH, Boesch C (eds) Monogamy: mating strategies and partnerships in birds, humans and other mammals. Cambridge University Press, Cambridge, pp 3-20

Rosell F, Czech A (2000) Responses of foraging Eurasian beavers Castor fiber to predator odours. Wildl Biol 6(1):13-21

Rosell F, Hovde B (2001) Methods of aquatic and terrestrial netting to capture Eurasian beavers. Wildl Soc Bull 29(1):269-274

Rosell F, Sanda J (2006) Potential risks of olfactory signaling: the effect of predators on scent marking by beavers. Behav Ecol 17(6):897-904

Rosell F, Schulte BA (2004) Sexual dimorphism in the development of scent structures for the obligate monogamous eurasian beaver (castor fiber). J Mammal 85(6):1138-1144

Rosell F, Thomsen LR (2006) Sexual dimorphism in territorial scent marking by adult eurasian beavers (Castor fiber). J Chem Ecol 32(6):1301-1315

Rosell F, Bergan F, Parker H (1998) Scent-marking in the Eurasian beaver (Castor fiber) as a means of territory defense. J Chem Ecol 24(2):207-219

Rosell F, Parker H, Steifetten $\varnothing$ (2006) Use of dawn and dusk sight observations to determine colony size and family composition in Eurasian beaver Castor fiber. Acta Theriol 51(1):107-112

Rosell F, Zedrosser A, Parker H (2010) Correlates of body measurements and age in Eurasian beaver from Norway. Eur J Wildl Res 56(1):43-48

Ruckstuhl KE (2007) Sexual segregation in vertebrates: proximate and ultimate causes. Integr Comp Biol 47(2):245-257

Ruckstuhl KE, Neuhaus P (eds) (2005) Sexual segregation in vertebrates-ecology of the two sexes. Cambridge University Press, Cambridge

Schoener TW (1979) Generality of the size-distance relation in models of optimal feeding. Am Nat 114(6):902-914

Sharpe F, Rosell F (2003) Time budgets and sex differences in the Eurasian beaver. Anim Behav 66(6):1059-1067

Shuster SM, Wade MJ (2003) Mating systems and strategies. Princetown University Press, New Jersey

Stearns SC (1989) Trade-offs in life-history evolution. Funct Ecol 3(3):259-268

Steyaert SMJG, Kindberg J, Swenson JE, Zedrosser A (2013a) Male reproductive strategy explains spatiotemporal segregation in brown bears. J Anim Ecol 82(4):836-845

Steyaert SMJG, Reusch C, Brunberg S, Swenson JE, Hackländer K, Zedrosser A (2013b) Infanticide as a male reproductive strategy has a nutritive risk effect in brown bears. Biol Lett: 20130624

Steyaert SMJG, Swenson JE, Zedrosser A (2014) Litter loss triggers estrus in a nonsocial seasonal breeder. Ecol Evol 4(3):300-310

Sun LX (2003) Monogamy correlates, socioecological factors, and mating systems in beavers. Monogamy: mating strategies and 
partnerships in birds, humans and other mammals. U. H. Reichard and C. Boesch. Cambridge, Cambridge University Press: 138-146 Wilsson L (1971) Observations and experiments on the ethology of the European beaver (Castor fiber L.). Viltrevy 8:115-266

Zedrosser A, Steyaert SMJG, Gossow H, Swenson JE (2011) Brown bear conservation and the ghost of persecution past. Biol Conserv 144(9):2163-2170
Zurowski W, Kisza J, Kruk A, Roskosz A (1974) Lactation and chemical composition of milk of the European beaver (castor fiber 1.). J Malmmal 55(4):847-850

Zuur AF, Ieno EN, Walker NJ, Saveliev AA, Smith GM (2009) Mixed effects models and extensions in ecology with R. Springer, New York 